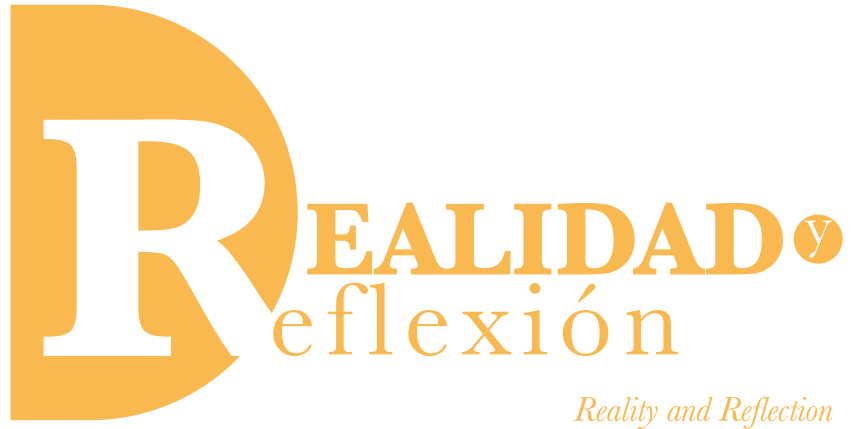

ISSN 1992-6510

Año 18, N 48, San Salvador, El Salvador, Centroamérica. Revista Semestral Julio-Diciembre 2018

YEAR 18, N 48, SAN SALVADOR, EL SALVADOR, CENTRAL AMERICA. SEMESTRAL JOURNAL JuLY-DECEMBER 2018

\title{
La economía creativa como ecosistema de innovación. Caso salvadoreño
}

\section{The Creative Economy as an Innovation Ecosystem. Salvadoran case}

\author{
Claudia Reneé Meyer \\ Licenciada en Mercadotecnia por la Universidad Dr. José Matías Delgado, El Salvador \\ Investigadora Asociada en Industrias Creativas, en el Instituto de Ciencia, Tecnología e Innovación \\ de la Universidad Francisco Gavidia, El Salvador \\ cmeyer@ufg.edu.sv \\ Víctor Miguel Cuchillac \\ Doctorando en Gestión Pública y Ciencias Empresariales \\ Máster en Informática Aplicada a Redes de la Universidad Francisco Gavidia \\ Ingeniero en Electrónica, por la Universidad Don Bosco, El Salvador \\ Investigador en Ingeniería y Tecnología, en el Instituto de Ciencia, Tecnología e Innovación \\ de la Universidad Francisco Gavidia, El Salvador \\ vcuchillac@ufg.edu.sv \\ Fecha de recepción: 27 de septiembre de 2018 \\ Fecha aprobación: 17 de diciembre de 2018
}

\section{RESUMEN}

Los ecosistemas de innovación se han convertido en las nuevas estructuras de organización e interrelación entre varios actores, para impulsar el emprendimiento y la innovación como sectores productivos no tradicionales. En ese sentido la emergente Economía creativa permite la comercialización de bienes y servicios derivados de las ideas y las actividades culturales (como son las tradiciones y las expresiones artísticas), siendo esto una oportunidad para mucho profesional recién graduado y emprendedor de incorporarse o crear actividades productivas, tal como se aborda de manera sucinta los casos de éxito en México y Colombia.

Debido a la ausencia y poca información en El salvador sobre el estado y la tendencia de la economía creativa, con este trabajo se buscar aportar en la epistemología e importancia de la implementación de los ecosistemas de innovación, y recopilar información de primera fuente del estado de la economía creativa; en especial, las acciones de los actores más relevantes de dicho esquema. Además, como parte de la metodología empleada para recabar las percepciones, experiencias, necesidades y los retos salvadoreños, se realizaron entrevistas a dos tipos diferentes de emprendimiento (una empresa con mayor tiempo de operación y personal, y una startup).

Palabras clave: Ecosistemas de innovación, Economía creativa, Innovación. 


\section{ABSTRACT}

Innovation ecosystems have become the new organizational structures and the interrelation between several actors, to promote entrepreneurship and innovation as non-traditional productive sectors. In that context, the emerging Creative Economy allows the marketing of goods and services derived from ideas and cultural activities (such as traditions and artistic expressions), this being an opportunity for many newly graduated and enterprising professionals to join or create productive activities such as success stories in Mexico and Colombia.

Due to the absence and a few information in El Salvador about the state and the trend of the creative economy, with this work we seek to contribute in the epistemology and importance of the implementation of innovation ecosystems, and collect information from the principal sources about state's creative economy; especially, actions of the most relevant actors of this scheme. In addition, as part of the methodology used to collect the perceptions, experiences, needs and Salvadoran challenges, interviews were conducted to two different types of entrepreneurship (a company with more operating time and staff, and a startup)

Keywords: national libraries, tecnology, information, virtual enviroment.

Keywords: innovation ecosystems, creative economy, innovation.

\section{Introducción}

El objetivo de este artículo consiste en exponer los conceptos epistemológicos del Ecosistema de innovación, y determinar el estado actual de los actores más relevantes de la Economía creativa en El Salvador, la cual se está gestando como un ejemplo real, (aunque no planificado) de un Ecosistema de innovación. La UNESCO señala la necesidad de "Integrar la cultura en los marcos de desarrollo sostenible" (Organización de las Naciones Unidas para la Educación, la Ciencia y la Cultura, 2018, pág. 2), reconociendo para ello las nuevas vetas y derroteros que plantean los servicios y los productos de la Economía creativa, así como sus bondades para coadyuvar a un desarrollo sostenible.

La evidencia empírica muestra que la Economía creativa puede ser ejemplo de la formación de Ecosistema de innovación convirtiéndose así en una oportunidad para mejorar las condiciones de vida de las personas, a partir de actividades con un alto componente tecnológico y que facilitan la inclusión y la inserción de talento joven en las mismas.
Debido a los cambios tan acelerados y holísticos que se producen desde la última centuria, es congruente que se produzcan a su vez nuevos cambios (que en muchas ocasiones son inelásticos y aleatorios), en: la economía mundial, el clima, el uso de las tecnologías, la modificación y el surgimiento de nuevos hábitos de consumo, el uso de los recursos naturales entre otros. Sin embargo, estos cambios o mutaciones aceleradas requieren que se haga un esfuerzo por orquestar la forma y la frecuencia con la cual se van integrando o superponiendo los cambios y los actores involucrados; ya que, el no hacerlo advendría un colapso en la calidad de vida de los seres humanos y el mismo planeta.

Consciente de lo anterior, el programa de Naciones Unidas para el Desarrollo (PNUD), propone sutilmente la sustitución del análisis de los entornos (económicos, ecológicos, sociales, etc..), como sistemas aislados, por el análisis basado en ecosistemas; ya que, la interrelación de un sistema específico con otros sistemas y actores es cada vez más palpable, y bajo la óptica del efecto mariposa (en donde una variable determinada, produce una influencia en un 
ámbito diferente al entorno intrínseco), se puede comprender que el crecimiento de una industria puede repercutir en muchos sistemas que antes no eran vinculados. Por ejemplo, el desarrollo y comercialización de los teléfonos inteligentes no solo tiene repercusiones en los mercados locales o internacionales; si no que afecta (cambiando o creando), los hábitos en los consumidores; también crea nuevos nichos de mercado, como "la televisión a la carta", (Netfilx, Amazon Prime, Hulu); disparan a su vez la extracción y comercialización de metales especiales como el paladio (De la Torre, Guevara, \& Espinosa, 2009, pág. 27), crean contaminación en el medio ambiente debido a los componentes de los desechos electrónicos.

Muchas veces ello requiere dinamizar la matriz productiva de un país, para el caso, en el tema de Economía creativa, potenciando la economía del conocimiento y la creatividad: convertirse en actores destacados en la producción y oferta de servicios, además de productos y contenidos vinculados a la Economía creativa; buscando con ello que los negocios relacionados a la creatividad y la propiedad intelectual crezcan. La dinamización de un sector, para el caso el de la Economía Creativa a partir de un Ecosistema de innovación, estimularía su alto potencial de diversificación y aprovechamiento de las tendencias mundiales, en mercados en constante cambio.

\section{Metodología}

En este artículo se busca responder las siguientes preguntas de investigación: ¿Qué es un ecosistema de innovación?, ¿cuáles son los componentes más relevantes de un ecosistema de innovación?, ¿cuáles son los ejemplos de ecosistemas de innovación relacionados con la economía creativa cercanos a El Salvador?, y ¿cuál es el estado de la economía creativa en El Salvador?

Para el desarrollo del trabajo de investigación, se partió de un abordaje epistemológico y un alcance del tipo exploratorio - descriptivo, porque el tema es muy nuevo (menos de cinco años), por lo cual se requiere del planteamiento del marco teórico que le sustenta, y luego construir a partir de la información obtenida los antecedentes, las condiciones y una aproximación al estado actual de la Economía creativa en el país. Para así determinar si esta actividad económica es una posible candidata para la puesta en marcha de un Ecosistema de innovación, que perita mejorar la calidad de vida de las personas relacionadas con esta actividad económica. El análisis de la información implicó la búsqueda y consulta directa de fuentes primarias, siendo la mayoría en este caso instituciones gubernamentales $y$ organizaciones internacionales; también, se construyó un instrumento (un cuestionario semi abierto) y una entrevista a las empresas relacionadas con actividades circunscritas a la Economía creativa.

Debido a que en el país no existen muchas empresas dedicadas a la Economía creativa, se optó por ubicar emprendimientos en esta área, y los sujetos a quienes se entrevistó fueron seleccionados bajo los criterios de una muestra no aleatoria, no probabilística, en dónde se consideró a empresas con bastante y poco personal, así como empresas recientes y no recientes. Ya con la información recolectada se realizó una matriz de comparación para determinar las características similares y diferentes, encontrando más elementos comunes que muchas diferencias. 


\section{Resultados}

Los ecosistemas de innovación son la evolución natural de los clústeres tecnológicos y los polos de desarrollo, debido a las siguientes razones: el acelerado cambio producido por la innovación en los productos y los procesos; la sinergia que desarrollan proveedores y clientes en las transacciones que establecen para ser competitivos; y la oportunidad que brindan el desarrollo tecnológico y su consumo. Cuando se emplea el concepto ecosistema de forma intrínseca se habla de la interacción y los beneficios que establecen los operadores de un sector empresarial para ser competitivos. La innovación a su vez permite crear nuevas necesidades y oportunidades efectivas de suplirlas, abriendo con ello nuevos mercados y puestos laborales, coadyuvando con esto el bienestar de las economías que logran consolidar uno o varios ecosistemas de innovación, en especial la incorporación del sector joven y la participación de mujeres, como se expondrá más adelante.

La Economía creativa es la acción productiva en la cual las ideas, las actividades tradicionales, $\mathrm{y}$ artísticas permiten la comercialización de bienes y servicios como: las artesanías, las producciones audiovisuales, las presentaciones artísticas, la industria de la moda, los videojuegos y similares. Sin embargo, convertir la Economía creativa en un Ecosistema de innovación efectivo, requiere de la articulación y la sinergia del sector privado, el sector público y la academia. En este trabajo se sintetizan dos experiencias notables para el desarrollo de Economía creativa, el Plan maestro para la Ciudad Creativa Digital (CCD) en México y la Ruta $\mathrm{N}$ del Centro de Innovación y Negocios de Colombia, las cuales no están geográficamente próximas, pero muestran elementos comunes en su administración e implementación.

Al esbozar el estado actual de la Economía creativa en El Salvador se encontró que existen acciones por parte del sector público que no están articuladas ni planificadas, las cuales endeblemente comienzan a incentivar y fortalecer los productos y servicios que pueden comercializarse bajo el concepto de Economía creativa, y estas acciones se enfocan principalmente en el otorgamiento de fondos y la formación básica. La academia también se encuentra sin articularse con el sector privado y público, formando un pequeño porcentaje de profesionales en temáticas contempladas en la Economía creativa, pero sin un seguimiento una vez graduados.Por su lado, el sector privado es muy parco para incursionar en esta área, y es por ello que es más común encontrar emprendimientos pequeños y medianos, los cuales expusieron en las entrevistas similares adversidades y necesidades, vinculadas a los aspectos que conforman un Ecosistema de innovación.

\section{Desarrollo de la discusión científica}

\section{¿Qué es un ecosistema de innovación?}

Para comprender el concepto de ecosistema innovación es necesario usar la premisa de los clústeres empresariales que Michael Porter definió en la década de los años 80, "Los clúster son concentraciones geográficas de empresas e instituciones interconectadas, que actúan en determinado campo" (Porter, 1999, pág. 32), Sin embargo, debido a la evolución de los clústeres empresariales y su interacción en un entorno 
más globalizado y el impacto en los recursos naturales, fue oportuno utilizar un nuevo concepto para describir la simbiosis y la sinergia del nuevo estado de esos clústeres empresariales o polos de desarrollo.

Este nuevo concepto de ecosistema de innovación, fue acuñado y utilizado por Tim Draiming cuando se inspiró en un informe que exponía la vinculación entre las abejas y los árboles, en dónde se evidenciaba la correlación y la interdependencia de estos dos actores para la superveniencia de ambos (Ecoticias, 2016). El concepto está formado por ecosistema e innovación, y aunque existen variantes en la definición de ecosistema (porque las primeras definiciones no incluían la vinculación con elementos que no estuvieran vivos), La definición propuesta por Daniel Puig es más conciliadora:

\section{El ecosistema es una unidad formada por} factores bióticos (o integrantes vivos como los vegetales y los animales) y abióticos (componentes que carecen de vida, como por ejemplo los minerales y el agua), en la que existen interacciones vitales, fluye la energía y circula la materia. (Puig, 2017).

La innovación no es un concepto nuevo, esta característica intrínseca al ser humano le ha permitido a lo largo de las centurias hacer cambios significativos en la agricultura, la vestimenta, la medicina, y las demás áreas. En un contexto productivo la innovación puede ser definida de la siguiente manera:

Una innovación es la introducción de un nuevo, o significativamente mejorado, producto (bien o servicio), de un proceso, de un nuevo método de comercialización o de un nuevo método organizativo, en las prácticas internas de la empresa, la organización del lugar de trabajo o las relaciones exteriores. (OECD/European Communities, 2005, pág. 56).

Acorde a lo anterior las actividades de innovación son muy variadas; ya que, pueden aparecer en cualquier momento o proceso dentro de una empresa; sin embargo, las actividades de innovación no son eventuales, si no que están sistematizadas por un proceso científico (aludiendo al método científico), el manual de Oslo expone que: "Las actividades innovadoras se corresponden con todas las operaciones científicas, tecnológicas, organizativas, financieras y comerciales que conducen efectivamente, o tienen por objeto conducción a la introducción de innovaciones". (OECD/European Communities, 2005, pág. 57). Sin embargo, no todas las actividades que se realizan en este sistema de innovación corresponden en sí mismas a la innovación, pero son actividades necesarias para realizar dicho proceso. También se define que cualquier tipo de innovación debe haber sido introducida, y por introducido se comprende que el producto ya mejorado debe haber ingresado al mercado.

Acorde al Manual de Oslo existen diferentes tipos de innovación, a continuación, se resumen los conceptos más importantes relacionados con la actividad productiva:

- Innovación de producto: Cuando se realiza un aporte significativo en un bien o servicio nuevo, mejorando sus características técnicas o sus funcionalidades. La mejora se hace 
como resultado del conocimiento o aplicación de tecnología.

- Innovación de proceso: Cuando los cambios se aplican a los sectores de producción y distribución, introduciendo nuevas técnicas y tecnologías, así como, nuevos materiales que permitan reducir los costes y mejor la calidad.

- Innovación en Marketing: Cuando se emplea un nuevo método de comercialización, cambiando significativamente el diseño, el envasado, el posicionamiento la promoción o la tarificación, con el fin de incrementar las ventas y la fidelización de los clientes. Se incluye también nuevos canales.

- Innovación en organización: Cuando se realizan cambios en las prácticas y procedimientos de la empresa, modificaciones en el lugar de trabajo, aplicación de decisiones estratégicas con el propósito de mejorar los resultados mejorando la productividad o reduciendo los costes de transacción internos para los clientes y proveedores. La actualización en la gestión del conocimiento también entra en este tipo de innovación.

Al analizar el concepto y los tipos de innovación se observa que existe como resultado del proceso de innovación un resultado que puede ser: un producto, un servicio o la combinación de ambos. Evidentemente el producto es tangible y sus mejoras pueden estar relacionadas con las características físicas, las materias primas, el envase, etc. Por su parte el servicio es intangible e incluye las estrategias tomadas por la empresa, los cambios dentro de la organización, la política y la mística de atención al cliente entre otros.
Sin embargo, la innovación no es una acción exclusiva de las empresas, (o no debería serlo), ya que tanto emprendedores, empresarios y organizaciones gubernamentales deben innovar para ser competitivas, $y$ ofrecer productos $y$ servicios de calidad a sus clientes.

Al integrar dos los dos conceptos anteriores: el ecosistema y la innovación, se deben considerar que existen los actores bióticos como: las empresas privadas y los emprendedores, las instituciones públicas, los entes de financiamiento y las academias. Y los actores abióticos como: las políticas públicas, los incentivos fiscales, los convenios de cooperación, las alianzas estratégicas y el marco legal que provee la seguridad jurídica de los actores bióticos. Del concepto de innovación se extrae la dimensión tangible e intangible, Por lo que se puede inferir que: Un ecosistema de innovación es un espacio físico determinado en donde interactúan de manera dinámica e interconectados de manera vital las la administración pública, la academia, el sector privado y los entes de financiamiento, quienes son fortalecidos $y$ vinculados por medio de las políticas públicas, los convenios y el marco legal, para producir de manera creativa, eficaz y eficientemente materias primas, productos, procesos $y$ servicios con coproducción de valor.

\section{Importancia de los ecosistemas de innovación}

Si bien es cierto que los ecosistemas de innovación han contribuido al desarrollo de las economías que le han apostado a su implementación y desarrollo, cualquier tipo de ecosistema afecta directa o indirectamente a otros ecosistemas; ya existen estudios que alertan sobre la importancia 
de la sostenibilidad en función de los recursos naturales. Acorde a los resultados publicados por el equipo de investigadores del proyecto Evaluación de Ecosistemas del Milenio se ha encontrado que:

Los cambios realizados en los ecosistemas han contribuido a obtener considerables ganancias netas en el bienestar humano y el desarrollo económico, pero estos beneficios se han obtenido con crecientes costos consistentes en la degradación de muchos servicios de los ecosistemas, un mayor riesgo de cambios no lineales,y la acentuación dela pobreza de algunos grupos de personas. Estos problemas, si no se los aborda, harán disminuir considerablemente los beneficios que las generaciones venideras obtengan de los ecosistemas. (Millennium Ecosystem Assessment, 2005).

En el año 2000 el Secretario de General de las Naciones Unidas crea la Evaluación de los Ecosistemas del Milenio (formada inicialmente por más de 1,360 expertos de diferentes áreas), para abordar los impactos por los diferentes ecosistemas del planeta, en dónde se resumen algunos de los puntos que el consejo de la evaluación dio a conocer en su informe Estamos gastando más de lo que podemos: Capital natural y Bienestar humano (Consejo de la evaluación de los Ecosistemas del Milenio, 2005, pág. 3):

Todas las personas del mundo dependen de la naturaleza y de los servicios de los ecosistemas para poder llevar una vida decorosa, saludable y segura.

La pérdida de los servicios derivados de los ecosistemas constituye una barrera importante para el logro de los Objetivos de Desarrollo del Milenio de reducir la pobreza, el hambre y las enfermedades.

Con la tecnología y el conocimiento disponibles ya se puede reducir considerablemente el impacto de los seres humanos sobre los ecosistemas. Pero es improbable que aquellos se utilicen plenamente mientras se perciba a los servicios de los ecosistemas como gratuitos e ilimitados, y su valor total no sea tomado en consideración.

Para una mejor protección del capital natural se requerirán esfuerzos coordinados entre todos los sectores de los gobiernos, las empresas y las instituciones internacionales. La productividad de los ecosistemas depende de las políticas que se apliquen, incluidas las relativas a inversiones, comercio, subsidios, impuestos y regulación.

En función de garantizar una sostenibilidad a largo plazo de los recursos naturales y el augurio de un bienestar humano para las futuras generaciones, es necesario que los emprendimientos y las acciones productivas estén demarcadas en las consideraciones de los ODS. En el informe titulado Ecosistemas y Bienestar Humano. Oportunidades y desafíos para las empresas y la industria, se aborda la relevancia que tienen las empresas y la industria en operar de manera coherente con la vinculación de los ecosistemas. (Evaluación de los Ecosistemas del Milenio,, 2005, págs. 2-5).

Los negocios no pueden funcionar si los ecosistemas y los servicios que ellos brindan 
- como agua, biodiversidad, fibra, alimentos y clima- son degradados o no están en equilibrio" - Consejo Empresario Mundial para el Desarrollo Sostenible.

Emergerán nuevas oportunidades de negocios a medida que aumente la demanda de maneras más eficientes o diferentes de utilizar los servicios de los ecosistemas con vistas a mitigar los impactos o a rastrear o comercializar los servicios.

Los negocios están en condiciones de ser una fuerza muy positiva en la respuesta a estos desafíos a través de la búsqueda de nuevas oportunidades de negocios y nuevos mercados, la reducción de las huellas que dejan sus operaciones sobre el medio ambiente, el desarrollo y despliegue de nuevas tecnologías y el establecimiento de asociaciones efectivas.

\section{Referencias regionales de ecosistemas de innovación}

La apuesta teórica por este tipo de organismos vivos de desarrollo sostenible cuenta ya con importantes experiencias de implementación a nivel mundial como la de Silicon Waldi (Israel), Zhongguancun (China), Electronics city (India), entre otros. Latinoamérica no está exenta de no tener experiencias propias, dado que sí el punto de partida es crear un entorno armónico y propicio para el desarrollo empresarial sostenible y de alto impacto a través de la innovación, la región cuenta con la materia prima indispensable: el talento y la voluntad humana. Por lo que de manera resumida se abordarán a continuación un par de experiencias latinoamericanas.

\section{Experiencia México: Plan maestro para la Ciudad Creativa Digital (CCD)}

\section{La iniciativa dice de sí misma que:}

Como definición señalan que: "Desde su concepción, CCD fue diseñada como un ecosistema, como un sitio propicio para crear y compartir conocimiento y oportunidades de desarrollo de alto impacto en temas productivos, sociales y culturales." (Ciudad Creativa Digital. Guadalajara, s/f).

Destacan en su concepción y funcionamiento la integración de aspectos financieros, formativos y de promoción, como la disposición para emprendedores de un capital de riesgo fondeado tanto por el gobierno, la empresa privada y otros institutos de emprendimiento (CCD Ventures); una incubadora perfilada para atender emprendimientos netamente digitales provistos de capital inicial a través del mismo CCD; la formación es vista como la vía para disponer del recurso humano idóneo básico y/o especializado, a través de la articulación y puesta en marcha de actividades pedagógicas que han visto su germen en la conciliación de intereses y formas entre los académicos y el sector empresarial (Modelo educativo Ingenium); a lo anterior se suma la 
importancia de la visualización y la presencia en nuevos mercados, así como la inserción de estas nuevas visiones y aprendizajes en el fortalecimiento de los emprendimientos locales a fin de contar con una visión global de desarrollo.

\section{Experiencia Colombia: Ruta N, Medellín. Centro de Innovación y Negocios}

Se conciben a sí mismos como:

Desarrollamos distintos programas y servicios para facilitar la evolución económica de la ciudad hacia negocios intensivos en ciencia, tecnología e innovación, de forma incluyente y sostenible. De esta manera buscamos articular y dinamizar el ecosistema de innovación de Medellín, haciendo énfasis en cuatro ingredientes clave: la formación del talento, el acceso a capital, la generación de la infraestructura necesaria y el desarrollo de negocios innovadores. Así, promovemos una cultura innovadora, la generación de empleo, el fortalecimiento de las instituciones, la formación del talento y el acceso a mercados. Nuestro propósito principal está orientado a mejorar la calidad de vida de los habitantes de la ciudad a través de la innovación. (Ruta N Medellín. Centro de innovación y negocios, s/f).

En esta experiencia, ellos han definido como público (target) e intereses a los empresarios, la academia, los inversionistas y los estudiantes. Cada uno de estos sectores es atendido y/o articulado a través de las iniciativas de Landing empresarial (atracción de nuevas empresas), Red de acceso a mercados (conectividad), Laboratorio de innovación (espacios de metodologías y herramientas dirigidos a innovación), CDC
Salud (emprendimientos innovadores en salud) y Laboratorio vivo (como un modelo evolucionado de ferias y ruedas de negocio) (Ruta n Medellín. Centro de innovación y negocios., s/f).

Tanto la experiencia mexicana como la colombiana, estando ambas en ubicaciones geográficas distantes, coinciden en puntos cruciales en su gestión y desarrollo:

- El foco de interés es la persona, los ciudadanos, su bienestar concebido como la suma de lo social y lo económico.

- Visión de largo plazo: la operatividad se encuentra sustentada en la mirada larga de dónde se desea estar, como "comunidad", compartiendo todos los involucrados la misma visión.

- Gobernanza compartida: ausencia de una figura rectora, más bien se traducen en consejos o juntas de administración, compuestas por representaciones de todos los actores involucrados.

- Los procesos se deben a la consecución eficiente y eficaz de los resultados: prima la agilizada, flexibilidad y comunicación activa entre los integrantes del ecosistema.

- La articulación como gestión: su accionar derivado a partirdela activacióny fortalecimiento de instancias en pro de metas específicas.

- Las sinergias entre diversidad de instancias, cada una desde su experticia, provocando con ellos escalamientos en los proyectos y nuevas cotas de desarrollo. 
- La auto mirada, el monitoreo e investigación, y la compartimentación de conocimiento: reflexiones críticas periódicas sobre los planes y metas alcanzados, el seguimiento efectivo a los proyectos y gestiones, la sistematización de las experiencias (gestión del conocimiento) sumado a la apertura de información.

\section{Los ecosistemas de innovación aplicados a la Economía creativa}

La evidencia empírica muestra que uno de los problemas más comunes en los países en vía de desarrollo que implementan estrategias y modelos de otras economías más robustas, es la omisión de adecuar y desarrollar el entorno para que la implementación sea robusta y sostenible. Es por ello, que la economía creativa debe estar circunscrita a un ecosistema de innovación en dónde diferentes actores realicen de manera efectiva e interactivas sus roles. Sin embargo, la Economía creativa es un concepto nuevo, en dónde es necesario que los actores más relevantes conozcan sus funciones y alcances, de manera que la interacción genere la productividad económica que pretende alcanzar.

\section{Economía creativa: definición y alcances}

Para el Banco Interamericano de Desarrollo BID (2017) la economía creativa o economía naranja se refiere a "el grupo de actividades a través de las cuales las ideas se transforman en bienes y servicios culturales y creativos, cuyo valor está o podría estar protegido por derechos de propiedad intelectual”. (Benavente \& Grazzi, 2017, pág. 9). La misma institución define el alcance de las actividades a ser consideradas como parte de esta economía, siendo grosso modo "(i) las actividades tradicionales y artísticas, (ii) la industria creativa y (iii) las actividades que brindan apoyo creativo a las industrias tradicionales" (Benavente \& Grazzi, 2017, pág. 2). Dichas actividades se desglosan como se muestra en la siguiente Figura n. ${ }^{\circ} 1$.

Es primordial denotar la importancia del componente cultural de esta economía, dadas las expresiones artísticas a las que alude en su puesta en marcha, lo cual no va en detrimento de lo económico, más bien se vuelve en la oportunidad de visibilizar y comunicar globalmente distintivos propios de una región, estando ahí su diferenciador.

Siguiendo con la trascendencia económica actual de este sector, la Confederación Internacional de Sociedades de Autores y Compositores (CISAC) reporta para el 2015 que:

Los ingresos generados por las industrias culturales y creativas en todo el mundo superan a los del sector de las telecomunicaciones (1,57 bill. de USD a nivel mundial), y sobrepasan el PIB de India (1.900 millones de USD). Sobre el total, los que más ingresos obtienen son la televisión (477.000 millones de USD), las artes visuales (391.00 millones), y los periódicos y revistas (354.000 millones). Con 29,5 millones de puestos de trabajo, las industrias creativas y culturales dan empleo al $1 \%$ de la población activa mundial. Los tres mayores generadores de empleo son las artes visuales (6,73 millones), los libros (3,67 millones) y la música (3,98 millones). (EY, 2015, pág. 8).

Adicionalmente, este sector tiene otras virtudes más sociales. La misma CISAC añade que: 


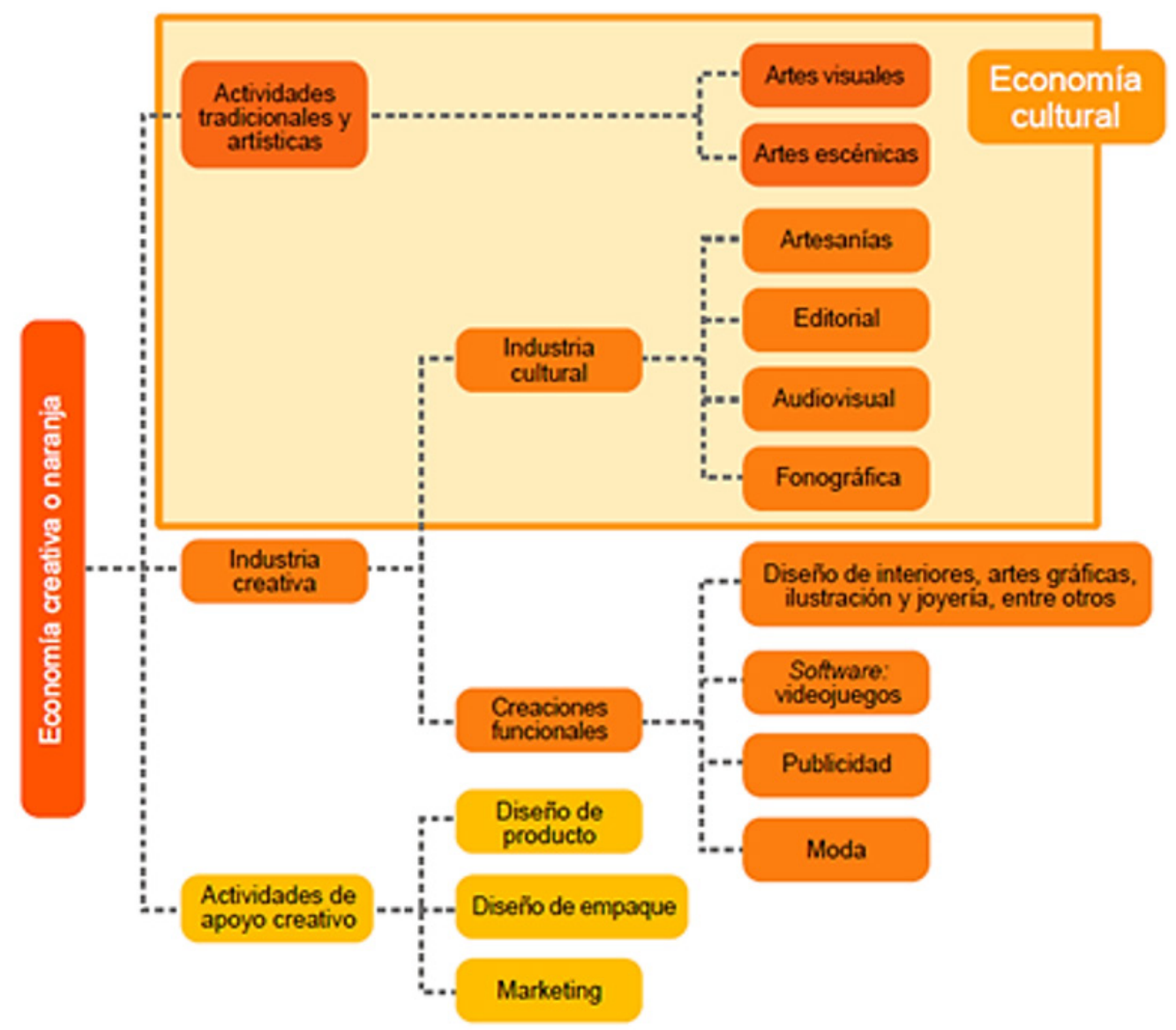

Figura n. ${ }^{\circ}$ 1. Alcance de las actividades de la Economía creativa. Fuente: Políticas públicas para la creatividad y la innovación: impulsando la economía naranja en América Latina y El Caribe (2017).

Las actividades creativas contribuyen significativamente a la generación de empleo joven y las trayectorias en las industrias creativas y culturales están relativamente abiertas a personas de todas las edades y procedencias. En Europa, los sectores de las industrias creativas y culturales emplean habitualmente a más gente de edades comprendidas entre los 15 y 29 años que cualquier otro sector. Las industrias creativas también tienden a favorecer la participación de las mujeres, a diferencia de las industrias más tradicionales. Los datos estadísticos provenientes del Gobierno de Reino Unido señalan que las mujeres representan más del $50 \%$ de los empleados en la industria de la música en el año 2014 (frente al 47\% de la población activa total). Por otra parte, las industrias creativas están impulsadas por la pequeña empresa $o$ particulares, dando lugar a empresarios ágiles e innovadores. (EY, 2015, pág. 8). 
Con respecto al comportamiento de la economía creativa en El Salvador, hace casi una década el Programa de las Naciones Unidas para el Desarrollo en E1 Salvador (PNUD), dedicó su Cuaderno de Desarrollo Humano No. 9 al estudio de las contribuciones económicas de la cultura al país (2009). ${ }^{1}$ Para dicha labor tomó como referencia data del Ministerio de Economía, el Banco Central de Reserva y la Dirección General de Estadísticas y Censos (DIGESTYC). El estudio es claro al manifestar que:

Al no haber en el país instrumentos estadísticos pensados para medir el campo de la economía de la cultura, las cifras oficiales resultan insuficientes para dar cuenta de ese ámbito económico que ha demostrado ser, en otras latitudes, muy dinámico en la generación de riquezas, empleo, bienestar, sentido de la vida y, por ende, desarrollo humano. Ocurre, pues, que en muchos casos no hay datos disponibles para cuantificar determinadas actividades o sectores de la economía cultural. Se tiene consciencia de que se necesita generar nuevos instrumentos para desarrollar indicadores monetarios y no monetarios sobre las actividades económicas de las distintas ramas del sector cultural. (PNUD El Salvador, 2009, pág. 16).

A pesar de estas dificultades, el estudio registra la realización de un primer cálculo de cuánto contribuye la cultura (lo creativo) a la economía nacional, es decir su perspectiva económica

1 Es importante denotar que hace diez años los abordajes teóricos partían por denominar "industrias culturales", habiendo evolucionado hasta denominarse hoy en día "economía creativa", el cual incorpora en su alcance las industrias culturales como parte de las industrias creativas. como generadora de empleo y riqueza. Es importante destacar que el estudio además subraya el potencial de este sector (desde 2009), para generar desarrollo local y nacional, a través de actividades culturales y relacionadas a estas; es decir, un sector productivo que a su vez suma a la solidificación de la identidad y el sentido de pertenencia. En la Figura n. 2 se muestra la estimación porcentualmente que dicho informe muestra para el aporte de la contribución de la cultura Producto Interno Bruto.

De igual forma, se registra en el informe el aporte económico del sector cultural en El Salvador por ramas de la estimación de la actividad económica, el cual es mostrado en la Figura n. ${ }^{\circ} 3$.

Ya en 2009 se estimaba en un $1.4 \%$ el aporte al PIB por parte de la cultura, destacando en este rubro con un mayor aporte el subsector de radio, televisión, cine y multimedia.

\section{La economía creativa salvadoreña como ecosistema de innovación}

Tal como se mencionó anteriormente, ya existen exitosos ecosistemas de innovación en diferentes partes del mundo, en donde la sinergia de diferentes actores permite la actividad comercial de productos tangibles y no tangibles de una manera más participativa para los diferentes sectores de la sociedad, en especial a los jóvenes recién graduados los cuales buscan incorporarse a actividades productivas. En la realidad salvadoreña, no todos los recién graduados de carreras y técnicos de nivel medio pueden ser absorbidos por las empresas y el sector público. Es por ello que el desarrollo de una Economía creativa permitiría que muchos jóvenes puedan 


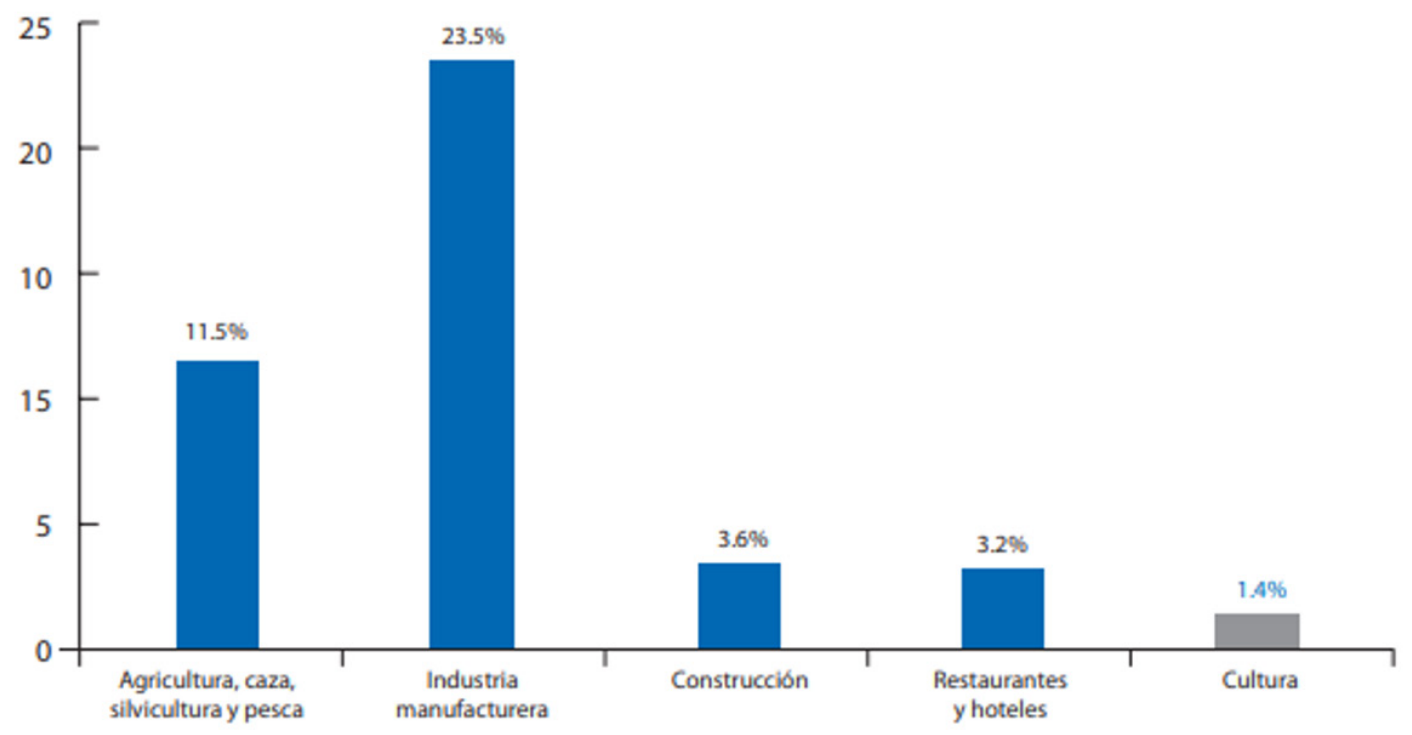

Figura n. $^{\circ}$ 2. Estimado del aporte de contribución al PIB de las actividades culturales. Fuente: Cuaderno sobre desarrollo humano No. 9 / PNUD El Salvador (2009).
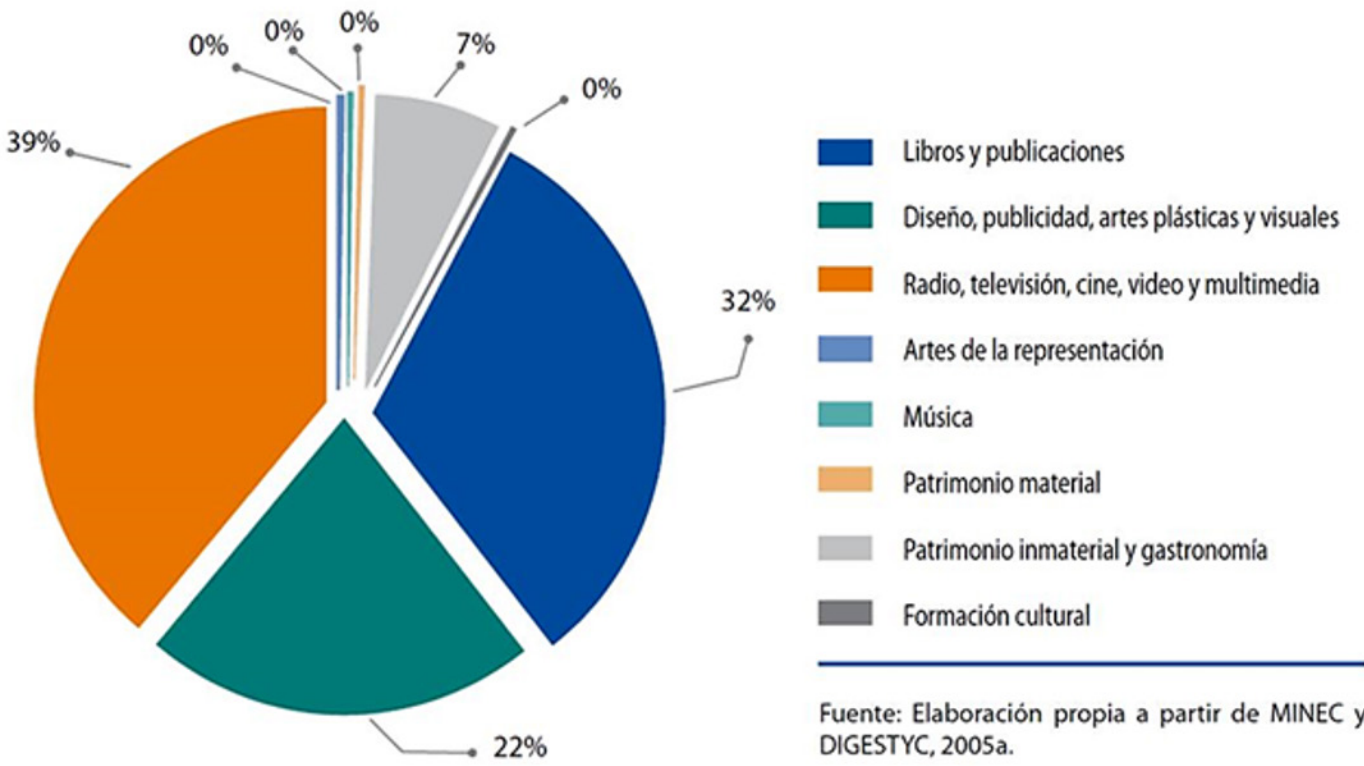

Fuente: Elaboración propia a partir de MINEC y DIGESTYC, 2005a.

Figura n. ${ }^{\circ}$ 3. Contribución al PIB por actividad económica. Fuente: Cuaderno sobre desarrollo humano No. 9 / PNUD E1 Salvador (2009). 
participar de actividades económicas, y dado que este segmento de la población posee una mayor vinculación con la tecnología, la incursión puede ser más rápida

Las dos experiencias vistas sobre Ecosistemas de innovación regionales tienen como característica lo tecnológico y lo digital como base de sus operaciones, productos y servicios; y en ese sentido la Economía creativa puede desarrollarse como un Ecosistema de innovación, debido a que basa su ejercicio a partir de productos y servicios derivados de la propiedad intelectual; es decir, creaciones inherentes a la creatividad del ser humano, mismas que pueden tener un alto componente tecnológico (como los videojuegos, la animación digital, lo audiovisual, entre otros).

Como resultado de lo anterior surge la siguiente interrogante: ¿En el Salvador se cuenta con un Ecosistema de innovación para la Economía creativa? A la fecha se puede perfilar el accionar público y privado de instrumentos $\mathrm{y}$ acciones claves que suman al desarrollo de una Economía creativa pero no necesariamente de un ecosistema de innovación. Sin embargo, es importante hacer notar que estos ecosistemas nos remiten como actores determinantes para su efectiva operación a la administración pública, el sector privado, la banca, los emprendedores, la academia; estos actores ya estén presentes en la configuración actual pudiendo articularse como un ecosistema de innovación. Entre las acciones más destacadas como Economía creativa a nivel nacional, pueden trazarse proyectos que van

2 Es de señalar que existen más actividades orientadas a la Economía creativa, pero debido al alcance de este estudio, solo se mencionará el MINEC. desde el financiamiento, emprendimiento y las actividades formativas.

\section{Primer actor: La administración pública}

\section{a. Ministerio de Economía (MINEC)}

A continuación, se describen brevemente algunas de las acciones desarrolladas por el Ministerio de Economía. ${ }^{2}$ En 2014, el Ministerio de Economía, en la Política Nacional de Fomento, Diversificación y Transformación Productiva, señala que:

... se realizó un ejercicio complementario de identificación de sectores productivos de interés para el desarrollo de iniciativas relacionadas al Fomento y la Diversificación, con el objetivo de construir las condiciones para el desarrollo de los mismos y que en un horizonte de tiempo más amplio puedan desarrollarse para convertirse en sectores de gran relevancia en la estructura productiva del país... (Ministerio de Economía de El Salvador, 2015, pág. 37).

Producto de este análisis, se refiere a las "industrias creativas" como sector prioritario para concentrar esfuerzos gubernamentales en este sector, considerado:

... como estratégico para el fomento y la diversificación productiva y la generación de empleo particularmente para la población juvenil, se sumaron a la propuesta los sectores de servicios especializados que tienen posibilidades de expansión en el aprovechamiento de las tendencias mundiales... (Ministerio de Economía de El Salvador, 2015, pág. 39). 
En diversas intervenciones públicas, funcionarios el MINEC han mencionado disponer de una hoja de ruta al 2030, a fin de posicionar al país como uno de los mayores productores de contenido creativo en Latinoamérica.

Una de las actividades que más se destacan son los premios Pixels, los cuales desde 2012 a la fecha, se han estado desarrollando y cuyo premio en su categoría Profesional, otorga fondos de cofinanciamiento no reembolsable para la producción y la comercialización de animaciones, videojuegos y audiovisuales. Al 2017 se registran 71 proyectos apoyados, desglosados de la siguiente manera: 33 animaciones, 16 videojuegos y 22 audiovisuales, con una inversión de USD 3,755,000.00; facilitando con esto, la creación de 48 empresas y 1,840 empleos en el sector (Dirección de innovación y calidad, 2018). De esta forma se impulsa la formalización del sector, la realización de producciones, el empleo formal, los emprendimientos, todo ello a partir de un instrumento de financiamiento.

Adicionalmente, el MINEC reporta el programa Pixels Caps, concebido como una formación dirigida para desarrollar las habilidades específicas demandadas por la parte empresarial. Y concordancia con esto, se han realizado a la fecha tres ediciones de Pixels Caps Animación y la primera edición de Pixels Caps Videojuegos, habiendo a la fecha 128 estudiantes aprobados entre ambas actividades (Dirección de Innovación y calidad, s/f).

\section{b. Ministerio de Cultura}

Esta es una instancia muy interesante; ya que, por su línea de acción, mucha de su operación pudiera circunscribirse como Economía creativa, por ejemplo: las actividades tradicionales $y$ artísticas, y la industria cultural por sí mismas son actividades que mueven directamente a los municipios, artesanos, empresarios y gobiernos locales. En este ámbito, se destacan cinco elementos dinamizadores presentes y a futuro: el proyecto del Instituto Superior en Artes, el Centro Nacional de Artes (CENAR), la creación de una cuenta satélite, fondos para proyectos y la Ley de cultura; estos elementos se adscriben a la gobernanza, el marco jurídico, el financiamiento y la formación para el soporte del sector. Sobre ello, el informe de Rendición de cuentas 2014-2017 de la entonces Secretaria de Cultura, convertida ahora en Ministerio, amplía sobre esos aspectos, los cuáles se refieren sucintamente. (Secretaria de cultura de la presidencia, 2017, págs. 20, 22, 24).

Al respecto del Instituto Superior en Artes (ISAR) se ha realizado a la fecha: un diagnóstico, un estudio de mercado, el diseño del modelo educativo, el diseño curricular de la oferta académica inicial (tres técnicos -desarrollo de producto artesanal, producción audiovisual, gestión de las artes y la cultura-, y un profesorado -educación artística-), y el diseño el marco normativo y legal del ISAR (Secretaria de cultura de la presidencia, 2017, pág. 20). Por otra parte, es importante mencionar las actividades del Centro Nacional de Formación en Artes, que brinda formación no reglada de carácter artístico en diversas disciplinas

Sobre el Fondo Nacional Concursable para la Cultura y las Artes (FONCCA), se ejecutaron $\$ 50,000.00$ en 2016 para la realización de proyectos teatrales y plásticos. (Secretaria de cultura de la presidencia, 2017, pág. 24). 
Sobre la Cuenta Satélite de Cultura ${ }^{3}$,se reporta la suscripción de convenio con el Banco Central de Reserva y el Ministerio de Economía para tal propósito, quedando conformada la Comisión de la Cuenta Satélite de Cultura de E1 Salvador. En 2016 se estableció el clasificador de actividades económicas culturales y el clasificador de productos culturales para dos sectores: libros y publicaciones, y el sector audiovisual. (Secretaria de cultura de la presidencia, 2017, pág. 25) Este proyecto en particular encuentra un eco en la advertencia realizada por el PNUD (2009) al respecto de la dificultad de contabilizar económicamente la actividad cultural; casi 10 años después se trabaja ya en ello.

Un ecosistema de innovación requiere de datos que guíen su rumbo y las actividades de investigación que permitan el desarrollo efectivo de dicho ecosistema. La recién aprobada Ley de cultura (2016) en su artículo 37 se refiere al Observatorio nacional de cultura (el cual idóneamente puede nutrirse, entre otras fuentes, de la data de la cuenta satélite de cultura) como instancia a crearse:

\footnotetext{
3 Las cuentas satélites son "son una extensión del sistema de cuentas nacionales, comparten sus conceptos básicos, definiciones y clasificaciones. Permiten ampliar la capacidad analítica de la contabilidad nacional a determinadas áreas de interés socioeconómico de una manera flexible y sin sobrecargar o distorsionar el sistema central."Para más información, consultar el siguiente recurso en línea: https://www.dane.gov.co/index.php/estadisticas-portema/cuentas-nacionales/cuentas-satelite. En cultura se destaca el trabajo del CAB -Convenio Andrés Bello-, el cual "es un organismo con personería jurídica internacional, intergubernamental, creado en virtud del Tratado suscrito en Bogotá, el 31 de enero de 1970, sustituido en Madrid en 1990". (Para más información consultar el siguiente enlace: http://convenioandresbello.org/inicio/que-esel-cab). Este busca "favorecer el fortalecimiento de los procesos de integración y la configuración y desarrollo de un espacio cultural común. Busca generar consensos y cursos de acción en cultura, educación, ciencia y tecnología, con el propósito de que sus beneficios contribuyan a un desarrollo equitativo, sostenible y democrático de los países miembros." Tomado del sitio (http:// convenioandresbello.org/inicio/que-es-el-cab/)
}

Se establecerá el Observatorio Nacional de Cultura como unidad especializada de la institución del Estado que vele por la cultura en el país, que se encargará de la recolección, tratamiento, análisis y divulgación de información de estadísticas y estudios provenientes de cada una de las unidades e instituciones dedicadas al desarrollo, protección y promoción del derecho humano a la cultura. (Asamblea legislativa de E1 Salvador, 2016).

\section{c. Centro Nacional de Registros}

La Política Nacional de Propiedad Intelectual, creada en 2014, busca "Posicionar la propiedad intelectual como elemento clave para el desarrollo nacional, que contribuya al mejor aprovechamiento de la capacidad de su población para la creación de conocimiento, y genere condiciones para mejorar la posición competitiva..." (Centro Nacional de Registros, 2015, pág. 7). Esta Política, entre sus ejes estratégicos y líneas de acción definidas, conlleva la "promoción del desarrollo cultural, fomento de las industrias creativas y artísticas, protección de la biodiversidad, del patrimonio, del conocimiento y expresiones culturales de los pueblos indígenas" (Centro Nacional de Registros, 2015, pág. 8).

Vinculando este accionar dentro de la Economía creativa, y al ser la propiedad intelectual el elemento clave en su operación, un indicador relevante para este sector vendría a ser la cantidad de depósitos (derecho de autor) y los contratos inscritos referidos a los acuerdos productos de derecho de autor. En siete años, el comportamiento se muestra en el siguiente cuadro: 


\section{Cuadro n.o 1}

Cuadro de depósito de obras artísticas y literarias.

\begin{tabular}{c|c|c|c|c|c|c|c|c|c}
\hline Año & $\mathbf{2 0 1 0}$ & $\mathbf{2 0 1 1}$ & $\mathbf{2 0 1 2}$ & $\mathbf{2 0 1 3}$ & $\mathbf{2 0 1 4}$ & $\mathbf{2 0 1 5}$ & $\mathbf{2 0 1 6}$ & $\mathbf{2 0 1 7}$ & Total \\
\hline Depósitos & 567 & 599 & 583 & 731 & 641 & 899 & 665 & 659 & 5,344 \\
\hline Contratos inscritos & 27 & 66 & 11 & 33 & 20 & 30 & 21 & 29 & 237 \\
\hline
\end{tabular}

Fuente: Elaboración propia con base a datos del Centro Nacional de Registro (Centro Nacional de Registros, 2018).

En el depósito de obras artísticas y literarias el sistema local no distingue entre audiovisuales, videojuegos, novelas, teatro, etc., sino más bien registra solo cantidades globales. Luego para visualizar la trascendencia de estos números, para el año 2016 la Población Económicamente Activa (PEA) estaba integrada por 2.9 millones de personas (Pacas, 2017) refiriendo esta data versus los depósitos de autor de dicho año, solo el 0.022\% de la PEA depositó obra en dicho año; luego la relación porcentual respecto a la inscripción de contratos sería muchísimo menor.

\section{Segundo actor: La academia}

Tanto las universidades privadas como las instituciones de educación superior públicas ofertan disciplinas formativas vinculadas directamente a la Economía creativa; al abordarse desde las áreas de conocimiento definidas por el Ministerio de Educación, se evidencia que su actividad está inmersa tanto en las ciencias sociales, en las humanidades, el arte y diseño, la educación, como en las ingenierías y tecnologías; convirtiendo así la Economía creativa en un elemento de abordaje inter, trans y multidisciplinario, desde la perspectiva académica.
Al respecto de las actividades formativas, tomando como referencia el alcance de las actividades contempladas como economía creativa, en particular las vinculadas a las actividades tradicionales y artísticas, y la industria creativa, a partir de los Resultados de la información estadística de instituciones de educación superior 2016, se observa lo siguiente: (Dirección Nacional de Educación Superior, 2017, págs. 19, 106-107, 113-115).

- La matrícula total reportada ascendió a 180,955 estudiantes.

- En las carreras referidas a la parte de Arte y Arquitectura (Arquitectura, Arte y diseño, Artes plásticas, Diseño ambiental, Diseño artesanal, Diseño gráfico, Diseño industrial, Artes escénicas, Patrimonio); la matrícula estudiantil ascendió a 8,227 personas, estando la mayor población en Arquitectura (3,778 estudiantes).

- En Humanidades, considerando solamente la maestría en Cultura centroamericana, las Licenciaturas en Lenguaje y literatura, y en Letras, y el Técnico en Artes liberales; la matrícula estudiantil ascendió a 679 personas, estando la mayor población en la licenciatura en letras (388 estudiantes). 
- En Tecnología, considerando exclusivamente la Licenciatura y el Técnico en Animación digital, más el Técnico en Multimedia; la matrícula estudiantil ascendió a 410 personas, estando la mayor población en el técnico en multimedia (224 estudiantes).

- En Educación, considerando el Profesorado en Educación artística y el Profesorado en Lenguaje y literatura; la matrícula estudiantil ascendió a 186 personas, estando la mayor población en el profesorado en lenguaje y literatura (168 estudiantes).

- En Ciencias Sociales, considerando la Licenciatura y el Técnico en Publicidad; la matrícula estudiantil ascendió a 244 personas, estando la mayor población en el técnico (215).

Después de realizar la extrapolación anterior, la población estudiantil vinculada a disciplinas de la Economía creativa, asciende a 9,746 estudiantes, estando la mayor concentración en el área de Arte y Arquitectura (84\%); y a su vez, estos estudiantes forman el $5.4 \%$ del total de matrícula.

La academia es un actor clave en el desarrollo de la innovación (en cualquiera de los tipos comentados con anterioridad); ya que, no solo aporta la formación de capital humano con las competencias demandadas y proyectadas, sino que también fungen como observatorios de las necesidades, características y nuevas tendencias en un ecosistema de innovación. La academia debe estar vinculada con otros actores como son la gestión pública y el sector privado. Esta vinculación de la academia se muestra en la siguiente figura como la función del sistema público de educación y de investigación.

En cuanto al quehacer de la investigación, el documento de Indicadores de ciencia y tecnología El Salvador 2016. Estadísticas sobre actividades científicas y tecnológicas e investigación y desarrollo sector educación superior (2017), no registra actividades específicas en las áreas de arte y diseño ni en educación; partiendo que pudiesen estar incluidas ya sea en ciencias sociales o en humanidades (no se tiene la certeza), existe la dificultad propia de la economía creativa de encajarle como disciplina en una o en áreas simultáneas para dilucidar el abordaje investigativo que pudiese haber tenido a la fecha este tema. En términos generales el gasto en Actividades Científicas y Tecnológicas (ACT), además del gasto de Investigación y Desarrollo $(\mathrm{I}+\mathrm{D})$, para un total de 39 instituciones de educación reportadas, se comportó como se muestra en el Cuadro n. ${ }^{\circ} 2$.

\section{Cuadro n. ${ }^{\circ} 2$}

Distribución del gasto en actividades cientificas y tecnológicas (ACT).

\begin{tabular}{c|c|c|c|c}
\hline $\begin{array}{c}\text { Área de conocimiento / } \\
\text { Criterios }\end{array}$ & $\begin{array}{c}\text { \% de gastos } \\
\text { asignados ACT }\end{array}$ & ACT en dólares & $\begin{array}{c}\text { Cantidad de } \\
\text { proyectos ACT }\end{array}$ & I+D en dólares \\
\hline Ciencias sociales & $36 \%$ & $103,936.51$ & 240 & $5,113.91$ \\
\hline Humanidades & $4 \%$ & $11,261.44$ & 22 & 166.75 \\
\hline
\end{tabular}

Fuente: elaboración propia con base a datos de Observatorio Nacional de Ciencia y Tecnología (2017) 
Luego el comportamiento el sector gobierno, según el documento Indicadores de ciencia y tecnología El Salvador 2016. Estadísticas sobre actividades científicas y tecnológicas e investigación y desarrollo sector gobierno (2017); de un total de 12 instituciones registra que: encuentra entre los 40 a 49 años de edad y tienen por mayoría la titulación de doctorado completo.

Es por ello que en los aspectos formativos es relativamente sencillo dilucidar cuáles son las disciplinas relacionadas a la Economía creativa,

\section{Cuadro n. 3}

Distribución de ACT para las áreas de Ciencias sociales y Humanidades. Fuente: elaboración propia con base a datos de Observatorio Nacional de Ciencia y Tecnología (2017).

\begin{tabular}{c|c|c|c}
\hline $\begin{array}{c}\text { Área de conocimiento / } \\
\text { Criterios }\end{array}$ & \% de gastos asignados ACT & $\begin{array}{c}\text { Cantidad de proyectos } \\
\text { ACT }\end{array}$ & I+D en dólares \\
\hline Ciencias Sociales & $50.40 \%$ & 21 & $1,215.20$ \\
\hline Humanidades & $2.39 \%$ & 10 & No se reporta \\
\hline
\end{tabular}

Fuente: elaboración propia con base a datos de Observatorio Nacional de Ciencia y Tecnología (2017).

Luego el documento Indicadores de vinculación de las Instituciones de Educación Superior (IES) con el entorno socioeconómico en E1 Salvador. Comparativo 2015 y 2016 (2017), no permite la extracción y el análisis de la información por área de conocimiento sino más bien por actividades (cantidad de prácticas, cantidad de emprendimientos, asesoramientos y consultorías, entre otras), por ende, no es factible visualizar cuáles de las áreas de conocimiento y disciplinas específicas dentro de las mismas, poseen una mayor vinculación con el entorno socioeconómico. Aparte, el documento Estudio de medición de la percepción de la ciencia y la tecnología con investigadores y docentes investigadores del sector Educación Superior (2017), consigna qué de 753 investigadores, el 13.2\% se dedica al área Humanística y el $26.8 \%$ a las Ciencias Sociales. El $40 \%$ de los 753 investigadores muestra bastante interés en cine, arte y cultura, siendo de este grupo la mayor concentración el rango que se idóneamente debería encontrar la misma sintonía en la parte investigativa, a fin de poder inferir cuál es el estadio real del abordaje académico investigativo de un sector que cuenta con oferta académica y laboral activa.

\section{Tercer actor: Los emprendedores}

A fin de contar con una aproximación al estado actual del emprendedor en el sector creativo, referido a los elementos que conformarían idóneamente un Ecosistema de innovación para las actividades de la Economía creativa, se entrevistó a dos emprendedores dedicados a las actividades audiovisuales. Para ello se elaboró una guía de entrevista que aborda los aspectos que conforman un Ecosistema de innovación, y mostrar así las condiciones actuales que influyen en la operatividad de este sector a partir de sus actores.

A continuación, se presenta la caracterización general de los entrevistados: 


\section{Cuadro n. ${ }^{\circ} 4$}

Datos generales de los entrevistados. Fuente: elaboración propia con base a los datos obtenidos a través de la guia de entrevista (2018)

\begin{tabular}{|c|c|c|}
\hline Datos generales & Emprendedor A & Emprendedor B \\
\hline a. Giro principal de la empresa & $\begin{array}{l}\text { Productora y comercializadora de films, } \\
\text { publicidad, capacitaciones. }\end{array}$ & $\begin{array}{l}\text { Actividades de producción } \\
\text { cinematográfica. }\end{array}$ \\
\hline $\begin{array}{l}\text { b. Fecha de creación (tiempo de } \\
\text { operación) }\end{array}$ & $\begin{array}{l}11 \text { de octubre de } 2010 \text { ( } 8 \text { años de } \\
\text { operación). }\end{array}$ & $\begin{array}{l}02 \text { de noviembre de } 2016 \text { ( } 2 \text { años de } \\
\text { operación). }\end{array}$ \\
\hline c. Facturación anual (2017) & $\begin{array}{l}\text { Promedio: de } 11 \text { a } 30 \text { mil dólares } \\
\text { americanos. }\end{array}$ & $\begin{array}{l}\text { Promedio: de } 31 \text { a } 50 \text { mil dólares } \\
\text { americanos. }\end{array}$ \\
\hline d. Cantidad de empleados & $\begin{array}{l}\text { No reportan empleados en planilla: } \\
\text { suele haber de dos a tres personas } \\
\text { "fijas" por servicios profesionales; las } \\
\text { demás contrataciones se realizan según } \\
\text { las necesidades de cada proyecto. }\end{array}$ & $\begin{array}{l}\text { No reportan empleados en planilla: } \\
\text { suele haber siete personas "fijas" por } \\
\text { servicios profesionales; las demás } \\
\text { contrataciones se realizan según las } \\
\text { necesidades de cada proyecto. }\end{array}$ \\
\hline e. Procedencia de los proveedores & Locales e internacionales. & Locales e internacionales. \\
\hline f. Procedencia de los clientes & Locales e internacionales. & Locales e internacionales. \\
\hline g. Tipo de productos que realizan & $\begin{array}{l}\text { Audiovisuales institucionales, } \\
\text { consultorías de comunicación, } \\
\text { sistematización de información de } \\
\text { proyectos. }\end{array}$ & $\begin{array}{l}\text { Productos cinematográficos, } \\
\text { sistematización de actividades. }\end{array}$ \\
\hline h. Premios o reconocimientos recibidos & $\begin{array}{l}\text { Becas para desarrollo de proyectos. } \\
\text { Premio Pixels } 2016 .\end{array}$ & $\begin{array}{l}\text { Premio Pixels } 2016 . \\
\text { Fondo holandés } 2018 .\end{array}$ \\
\hline $\begin{array}{l}\text { i. Uso de métodos/técnicas de } \\
\text { planificación empresarial }\end{array}$ & $\begin{array}{l}\text { Planifica dependiendo de los giros } \\
\text { o focos de atención internacional } \\
\text { (temáticas); realiza adaptaciones a } \\
\text { intereses de apoyos internacionales. }\end{array}$ & $\begin{array}{l}\text { No de forma general: se hace en base al } \\
\text { proyecto del momento. }\end{array}$ \\
\hline j. Actividades actuales de la empresa & $\begin{array}{l}\text { Atención a ONG. } \\
\text { Producciones independientes y co } \\
\text { producción independiente }\end{array}$ & $\begin{array}{l}\text { Producción de una serie de televisión } \\
\text { infantil (10 capítulos) para un cliente. } \\
\text { Producción de largometraje } \\
\text { documental sobre derechos sexuales y } \\
\text { reproductivos, para un cliente. }\end{array}$ \\
\hline $\begin{array}{l}\text { k. Intereses a los que les gustaría } \\
\text { dedicarse a futuro }\end{array}$ & $\begin{array}{l}\text { Vender servicios internacionales, } \\
\text { atraer inversiones al país que no } \\
\text { necesariamente sean salvadoreñas. }\end{array}$ & $\begin{array}{l}\text { Producción de cine: que existen } \\
\text { condiciones en el país para dedicarse } \\
\text { a eso: "Estamos haciendo lo necesario } \\
\text { (para sobrevivir) no lo que queremos". }\end{array}$ \\
\hline
\end{tabular}

Al respecto de la comprensión del alcance del concepto de innovación y si consideran que éstas son realizadas al interior de las iniciativas, la empresa A liga el concepto a las nuevas tecnologías y/o nuevos mercados, considerando que se realiza en cierta medida en las asistencias técnicas que brinda y en los servicios tecnológicos (procesos de corrección de color, post producción). La empresa B asocia el término a novedad, lo nuevo, como una forma de re pensar las operaciones y de superación de las formas del hacer común; comenta qué si bien 
no usan la palabra "innovación”, la consigna es “... hacer las cosas de la mejor manera posible bajo las condiciones que nosotros tenemos y que hagamos productos de calidad y competitivos en el mercado", para ello han realizado inversiones en equipo, dejar de ganar en salarios para realizar dichas inversiones, y pensar en procesos rigurosos de producción para asegurar el tema de calidad.

Sobre el conocimiento de ecosistemas de innovación como estructuras, la empresa A considera que puede referirse a "A una granja de diversidad de empresas que se dediquen a constantemente estar investigando en el mundo de las nuevas invenciones o los nuevos servicios, y hacer un pull integrado, pero en el área en este sentido en el área técnica y de nuevos servicios que vayan referidos o como integrarlos...". Para la empresa B adquiere connotaciones distintas, partiendo por aseveraciones sobre las dinámicas actuales del sector: " $\mathrm{Si}$ es un ecosistema donde convivir, cómo convivís con las tarifas bajas (...) No se puede hablar de un ecosistema de innovación si no estamos organizados (...) Creo que ecosistema no existe o sí existe pero es una mierda bien cabrona por la desorganización, los tarifarios (...) es una olla con agua hirviendo y cada quien es un cangrejo que se está jalando las patas, es una lucha que no es colectiva sino individual viendo cada quien como putas se salva".

Referido a las dificultades que han tenido para salir adelante como empresa, ambos casos coinciden en lo imposible de acceder a financiamientos por la poca comprensión del tipo de trabajo y los ciclos de producción de este tipo de actividades. Luego la empresa B, la de más reciente formalización, destaca lo difícil de la creación de una empresa en el país además de su correcta administración además del desconocimiento de los modelos de negocio que podrían aplicar; si bien señalan que el carácter formal les ha proveído de un mejor acceso a oportunidades y mercados. Luego la empresa A indica como una seria dificultad el que "No hay tarifas de servicios, los precios de las producciones se han venido para abajo, no se sale con los costos de las producciones"; ello lo atribuye a la desorganización del gremio y ausencias de normativas, adicionalmente resalta que es un problema los periodos de pago establecidos (de 60 a 90 días) y los atrasos en los pagos por los clientes.

Al consultarles si creían que existe una articulación actual entre gobierno, academia, banca, gremio y empresarios para dinamizar al sector, y si la considerarían necesaria, ambas empresas destacan el premio Pixels del Ministerio de Economía como iniciativa gubernamental; sin embargo, consideran que debe hacerse mucho más a partir de evaluar la condición actual de la industria, ir creando las bases de su desarrollo entre gobierno y empresa privada para una visión a largo plazo.

A la fecha, ambas empresas han recibió apoyo gubernamental a través del premio Pixels, y una del Centro de Desarrollo de Micro y Pequeñas Empresas (CDMYPE), a través de asesorías. De la banca o de gremiales no reportan beneficios a la fecha. Del sector académico les han apoyado en préstamos de instalaciones para filmaciones, asignación de pasantes, buscarles como docentes, pero estacan que no es algo sistemático. En otros apoyos, la empresa B señala que grupos o personas 
que a veces donan su trabajo y experiencia en la producción de una película.

$\mathrm{Al}$ respecto de qué tipo de apoyos o facilidades esperarían de los demás actores involucrados en un Ecosistema de innovación, señalan que:

- Gobierno: apoyos en facilitar asistencia a ferias, acercarles a los salvadoreños en el exterior y procurar la participación en eventos internacionales del sector como un conjunto de empresas salvadoreñas; adicional a fondos, la creación de legislaciones, la creación de una institución que dinamice la industria, que logre integrar a los que forman parte y que ayude a exportar el contenido.

- Academia: que exista una oferta de grado para este sector. Considerar a la empresa privada para los diseños de las currículas, que los graduados respondan a las necesidades actuales del sector; que dicha carrera no se convierta en algo de élite (propiciar becas o costos bajos), y atender las necesidades de especialización a través de la formación continua (talleres).

- Banca: líneas de créditos blandas (para la empresa y para momentos durante la producción). El tema de las aseguradoras salió a relucir en ambas empresas, pues manifiestan que no hay apertura para el aseguramiento de los equipos y las producciones.

- Gremialidad: visto desde dos perspectivas, la primera que gremiales como la ASI (Asociación Salvadoreña de Industriales) y COEXPORT (Corporación de Exportadores de El Salvador) incluyesen en sus afiliados el sector de audiovisuales o nuevas tecnologías (integrando animación, videojuegos y audiovisuales. Lo segundo, visto como la necesidad de organizar el rubro, el gremio, a fin de promover la existencia de la industria y el cuido de la misma entre sus miembros y promover la valorización adecuada del trabajo.

- Otros: que el Gobierno forme parte del programa Ibermedia a fin de acceder a fondos internacionales; promover el país como una locación en la que todo lo geográfico y los servicios son accesibles; promover la inversión en el sector audiovisual, "crear las condiciones para poder vivir del audiovisual”.

Sobre cómo idealmente debería coordinarse y trabajar este sector con otros actores, la empresa A señala que el audiovisual "Es un sector que puede incluir a muchos más a la hora de hacer producciones grandes. Por ejemplo, unir con el sector turismo por el uso de hoteles, catering, transportes, alquiler de vehículos", es decir ofertar el país como un lugar para que producciones internacionales puedan producirse desde el país. La empresa B visualiza la creación de una institución que vele por todos los temas del audiovisual, desde leyes, economía, financiamiento, que pueda ser una combinación entre lo privado y lo público.

Consultando cuáles serían las necesidades más urgentes, ambas empresas coinciden en la organización del sector, que ello pasa por el establecimiento de los tarifarios, conectarse entre empresa, que exista una visión y rumbo conjunto; la empresa B destaca la creación de una ley que sea para el fomento y regulación del sector. 
Por último, las empresas señalan que la importancia de apoyar este sector radica en que "El audiovisual es la herramienta más viable para poder visibilizar cualquier desarrollo, cualquier resultado, cualquier problemática”, y que además "El cine hace crecer a las sociedades, el cine es nuestro espejo, ahí nos vemos, no son historias de afuera somos nosotros los que nos vemos ahí y eso nos permite reflexionar, conectarnos y a la vez crecer".

\section{Discusión}

Los hallazgos reportados a partir de un primer examen de la Economía creativa en el país, a la luz de lo que idóneamente debería ser un Ecosistema de innovación, se puede ver en el Cuadro n. ${ }^{\circ} 5$.

\section{Conclusiones y recomendaciones}

- A la fecha, las actividades de Economía creativa a nivel nacional no son abordadas ni estructuradas como un Ecosistema de innovación propiamente. Si bien hay vinculación de instituciones, su propósito es para el cumplimiento de metas institucionales, enfocadas en visiones y logros diferentes. El reorientar y organizar estos esfuerzos bajo la visión de un Ecosistema de innovación facilitaría el abordaje y la dinamización integrada de este sector, además atraería a más participaciones de proveedores de servicios y productos, con lo que económicamente se estaría abriendo un nuevo y emergente campo económico para jóvenes recién graduados y emprendedores.

- La desarticulación de las instituciones públicas, la academia y sector productivo (empresas y emprendedores), dificulta la recolección de datos, lo cual hace que se invisibilice la acción económica, dificultando con ello el financiamiento por parte de la banca, la oferta a otros mercados de los productos y los servicios producidos, y la especialización en las competencias requeridas por el capital humano que labora en este sector

- En el sector académico se evidencia que existe una población de 9,746 estudiantes en formación de grado (Ministerio de Educación. República de El Salvador, 2017), preparándose en diversas actividades de la Economía creativa. Debe considerarse, además de ellos la población que se forma de manera autodidáctica y la población que cursa programas en línea o de forma presencial en academias locales $u$ otros programas, (las cuales son un número indeterminado debido a la falta de datos). Toda esta población es capital humano laboral presente y futuro, que en un momento buscará como integrarse en las cadenas de valor, ya sea como emprendedores o asalariados. Sin embargo, de continuar el esquema actual, muchísima de esta población no podrá ejercer con la formación obtenida. Y de allí otra razón para implementar un Ecosistemas de innovación; ya que, estos contemplan en su estructura la vinculación dinámica y efectiva con (como se observó en las experticias mexica y colombiana): la empresa privada, otras opciones de financiamiento y la facilitación de emprendimientos, a fin de dotar de la movilidad económica y humana necesaria al sector.

- La administración pública es uno de los actores más importantes para impulsar y fortalecer un Ecosistema de innovación y 


\section{Cuadro n. 5}

\section{Discusión al respecto de los hallazgos. Fuente: elaboración propia (2018)}

\begin{tabular}{|c|c|c|}
\hline Administración pública & La Academia & Emprendedores \\
\hline $\begin{array}{l}\text { - Si bien hay acciones e instancias claras } \\
\text { y claves ya perfiladas en el accionar de } \\
\text { la Economía creativa, estos esfuerzos } \\
\text { persiguen sus propios rumbos y } \\
\text { metas, careciendo de articulación. A } \\
\text { su vez, requiere de más acciones para } \\
\text { fortalecer el sector, necesidades que } \\
\text { salen de los mismos emprendedores. }\end{array}$ & 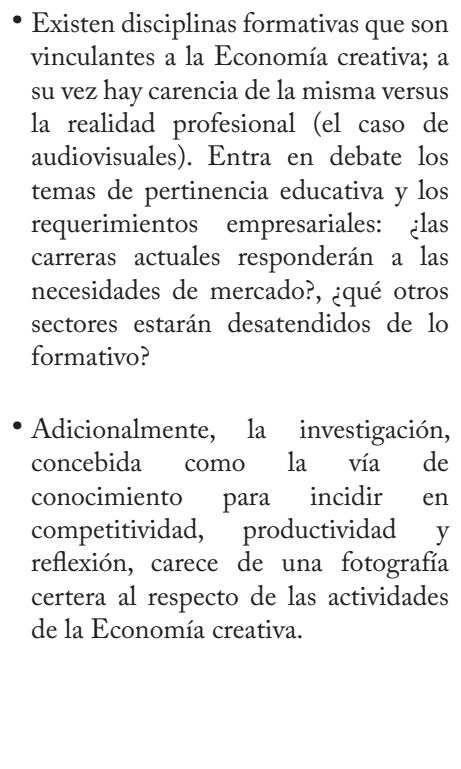 & $\begin{array}{l}\text { - Un posible ecosistema de innovación } \\
\text { cuenta con estos actores, en } \\
\text { diferentes estadios. Particularmente } \\
\text { el área de audiovisuales señala la } \\
\text { carestía de formación local, cosa } \\
\text { que efectivamente en la academia } \\
\text { no se reporta ésta disciplina en } \\
\text { instituciones de educación superior. } \\
\text { Los señalamientos observados pasan } \\
\text { por el sector privado (necesidad } \\
\text { de inversores e incentivos), } \\
\text { financiamiento (líneas especiales, } \\
\text { comprensión del sector tanto de la } \\
\text { banca como de las aseguradoras), lo } \\
\text { gremial (organizarse como sector } \\
\text { y ser adscrito como sector a otras } \\
\text { organizaciones), marco normativo } \\
\text { (la creación de nuevos cuerpos } \\
\text { legales para fomentar y dinamizar), } \\
\text { la incorporación a espacios } \\
\text { internacionales de fomento, apoyo } \\
\text { sostenido e integral del gobierno con } \\
\text { base a la situación actual. }\end{array}$ \\
\hline
\end{tabular}

debe consolidarse en su visión e intervención, la integración del resto de actores (empresasempresarios, la academia, la sociedad civil, las instituciones de financiamiento, los promotores, etc.), las condiciones y perfiles para la formación del capital humano, la creación de marcos regulatorios, el acceso a financiamiento e incentivos, la promoción en el exterior, entre otros.

- Si la Economía creativa basa sus operaciones en el capital intelectual, es necesario fortalecer las competencias en estas áreas, desde la formación básica (contenidos como ejes transversales o asignaturas), la formación de los docentes hasta la creación de actividades en educación media en dónde se desarrolle proyectos concretos. Las cifras salvadoreñas de propiedad intelectual son muy bajas; y aun cuando el Estado invierte capital económico en estimular esta industria, las cadenas de valor de la misma se operativizan, resultando en contenidos gráficos, literarios y musicales susceptibles y necesarios de protección intelectual para su debida comercialización. Es necesario en este momento una mayor sensibilización y articulación entre los actores de esta industria, para concientizar la importancia del registro de sus contenidos y la búsqueda de la comercialización de los mismos.

- Es imperante la creación de un observatorio sobre las actividades de la Economía creativa 
en El Salvador, esto permitirá: centralizar, actualizar y difundir la información estadística y económica, crear un espacio de intercambio y colaboración entre los actores, analizar y proponer modelos de gestión y políticas públicas, medir la competitividad y la innovación. Este observatorio podría iniciarse por la academia (instituciones privadas y públicas), el Ministerio de Economía, El Centro Nacional de Registros, El Ministerio de Educación, Ciencia y Tecnología, y la Secretaría de cultura de la Presidencia, representante de la Banca.

\section{Referencias bibliográficas}

Asamblea legislativa de El Salvador. (11 de agosto de 2016). Ley de cultura. Obtenido de Ministerio de cultura: http://www.cultura.gob. sv/ley-de-cultura/

Ateca Amestoy, V. (16 de junio de 2006). Economía de la Innovación Tecnológica. Obtenido de Departamento de fundamentos del análisis económico.: http://www. ehu.eus/vickyateca/notas_clase.pdf

Benavente, J. M., \& Grazzi, M. (2017). Políticas públicas para la creatividad y la innovación: Impulsando la economía naranja en América Latina. Washington, D.C: Banco Interamericano de Desarrollo.

Centro Nacional de Registros. (27 de noviembre de 2015). Politica Nacional de Propiedad Intelectual. Obtenido de http://www.cnr.gob.sv/ politica-nacional-de-propiedad-intelectual/

Centro Nacional de Registros. (2018). Cantidad de depósitos de derechos de autor y contratos registrados. San Salvador,E1 Salvador: Resolución de Oficina de Información y Respuesta.
Ciudad Creativa Digital. Guadalajara. (s/f). ¿Qué es CCD? Obtenido de Sitio Oficial de Ciudad Creativa Digital. Guadalajara: http:// ccdguadalajara.com/es_ES/

Consejo de la evaluación de los Ecosistemas del Milenio. (marzo de 2005). Estamos gastando más de lo que poseemos. Obtenido de https:// www.millenniumassessment.org/documents/ document.440.aspx.pdf

De la Torre, E., Guevara, A., \& Espinosa, S. (2009). Los teléfonos celulares una nueva mina de metales preciosos,. Revista Politécnica, 27.

Dirección de innovación y calidad. (19 de junio de 2018). Sitio Pixels. Obtenido de ¿Qué es PIXELS?: http://www.innovacion. gob.sv/pixels/index.php/2018-06-26-1939-26

Dirección de innovación y calidad. (s/f). ¿Qué es PIXELS? Obtenido de http://www.innovacion. gob.sv/pixels/index.php/2018-06-26-19-39-26

Dirección de Innovación y calidad.(s/f).PIXELS CAPS. Obtenido de Sitio Pixels: http://www. innovacion.gob.sv/pixels/index.php/pixelscaps/ pixelscaps

Dirección nacional de educación superior. (octubre de 2017). Resultados de la información estadística de instituciones de educación superior 2016. Obtenido de Ministerio de educación.: https://www. mined.gob.sv/index.php/2015-05-12-1529-13/send/713-informacion-estadisticade-educacion-superior/6448-resultados-dela-informacion-de-ies-2016 
Ecoticias. (20 de octubre de 2016). ¿̨Qué es el ecosistema de la innovación? Obtenido de Sitio oficial de Ecoticias: https://www.ecoticias. com/tecnologia-verde/170946/ecosistemainnovacion

Evaluación de los Ecosistemas del Milenio,. (2005). Ecosistemas y Bienestar humano. Oportunidades y desafíos para las empresas y la industria. Washington, DC: World Resources Institute.

EY. (diciembre de 2015). Tiempos de cultura. El primer mapa mundial de las industrias culturales y creativas. Obtenido de http://www. worldcreative.org/wp-content/uploads/2016/03/ EYCulturalTimes2015_ES_Download.pdf

Millennium Ecosystem Assessment. (2005). Evaluación de los ecosistemas del mundo. Obtenido de https://www.millenniumassessment.org/es/ About.html

Ministerio de Economía de El Salvador. (21 de mayo de 2015). Politica nacional de fomento diversificación y transformación productiva. Obtenido de http://www.minec.gob.sv/ descargas/politica-nacional-de-fomentodiversificacion-y-transformacion-productiva/

Ministerio de Educación. República de El Salvador. (2017). Resultados de la información estadística de instituciones de educación superior 2016. San Salvador. El Salvador: Cadena Cuscatlán.

OECD/European Communities. (2005). Manual de Oslo. Guía para la recogida e interpretación de datos sobre innovación. 3ra edición. España: Grupo Tragsa.
Organización de las Naciones Unidas para la Educación, la Ciencia y la Cultura. (2018). Repensar las políticas culturales. Creatividad para el desarrollo. París (Fracia): UNESCO.

Orozco, J. (2004). Innovation and Performance Improvements in the Cooperative Sector, Dinamarca: CINPE.

Pacas, A. (07 de abril de 2017). Diario El Salvador. com. Obtenido de https://www.elsalvador.com/ noticias/negocios/468545/cuantas-personastrabajan-en-el-salvador/\#link

PNUD El Salvador. (2009). Cuadernos sobre Desarrollo Humano 9. Desarrollo bumano y dinámicas económicas locales: Contribución de la economía a la cultura. San Salvador, El Salvador: Programa de las Naciones Unidas para el Desarrollo.

Porter, M. (1999). Los clúster y la competencia. Trend Management/Harvard Business Review, 22.

Puig, D. T. (2017). Los ecosistemas. Obtenido de Repositorio de material curricular libre: http://www.mclibre.org/otros/daniel_tomas/ diversificacion/ecosistemas/ecosistemas.pdf

Ruta N Medellín. Centro de innovación y negocios. (s/f). Somos el centro de innovación y negocios de Medellín. Obtenido de https://www. rutanmedellin.org/es/nosotros

Ruta n Medellín. Centro de innovación y negocios. (s/f). Nuestra oferta. Obtenido de https://www.rutanmedellin.org/es/oferta 
Secretaria de cultura de la presidencia. (mayo de 2017). Rendición de cuentas 2014 - 2017. Obtenido de Sitio web del Ministerio de cultura: http://www.cultura.gob.sv/rendicionde-cuentas-2014-2017/ 